\title{
PENGARUH MOTIVASI KERJA DAN IKLIM KERJA TERHADAP KEPUASAN KERJA DAN IMPLIKASINYA TERHADAP KINERJA TENAGA KEPENDIDIKAN INSTITUT PERTANIAN BOGOR
}

\author{
THE EFFECT OF MOTIVATION OF WORK AND WORK CLIMATE TO WORK SATISFACTION \\ AND IMPLICATIONS TO PERFORMANCE PERFORMANCE OF \\ EDUCATION BOGOR AGRICULTURAL UNIVERSITY
}

\author{
Diyanti $^{*}$, Musa Hubeis ${ }^{* *}$, dan M. Joko Affandi $\left.{ }^{* * *}\right)$ \\ *) Direktorat SDM dan Administrasi Umum, Institut Pertanian Bogor \\ Gd. Rektorat Kampus IPB Darmaga Bogor 166180 \\ ${ }^{* *}$ Departemen Manajemen, Fakultas Ekonomi dan Manajemen, Institut Pertanian Bogor \\ Jl. Kamper, Wing 2 Level 5 Kampus IPB Darmaga Bogor 166180 \\ $\left.{ }^{* * *}\right)$ PPM Jakarta \\ Jl. Menteng Jakarta
}

\begin{abstract}
Abstrak: Bogor Agricultural University supporting staff (known as tenaga kependidikan or tendik) is one of the Human Resources (HR) that have a strategic role in providing excellent services to the students and lectures. Therefore they need to have an adequate competence. Objective of this research is (1) analyze the influence of work motivation towardjob satisfaction of supporting staff, (2) analyze the influence of work climate toward job satisfaction of supporting staff and, (3) analyze the influence job satisfaction toward of supporting staff's performance in Bogor Agricultural University. Based on SEM-PLS analysis, it was known that work motivation and work climate significantly affected job satisfaction. Furthermore, job satisfaction significantly affected by the supporting staff performance in Bogor Agricultural University. In addition, $R$-Square value for job satisfaction was 0.458 . It means that work motivation and work climate has contributed positively to the satisfaction as much as $45.8 \%$, and the rest $54.2 \%$ was influenced by other factors. Furthermore, $R$-Square value for Supporting staff performan was 0.028. it means that supporting staff performance was positively influenced by job satisfaction as much as $2.8 \%$, and the rest $97.2 \%$ was influenced by other factors.
\end{abstract}

Keywords: climate, supporting staff, work motivation, supporting staff, SEM

\begin{abstract}
Abstrak: Tenaga Kependidikan (Tendik) Institut Pertanian Bogor (IPB) sebagai salah satu Sumber Daya Manusia (SDM) yang memiliki peran strategik dalam memberikan pelayanan, baik kepada mahasiswa maupun dosen perlu memiliki kompetensi memadai. Penelitian ini bertujuan (1) menganalisis pengaruh motivasi kerja terhadap kepuasan kerja Tendik, (2) menganalisis pengaruh iklim kerja terhadap kepuasan kerja Tendik, dan (3) menganalisis pengaruh kepuasan kerja terhadap kinerja Tendik IPB. Berdasarkan analisis SEM-PLS, diketahui bahwa motivasi kerja dan iklim berpengaruh nyata terhadap kepuasan kerja Tendik IPB, kepuasan kerja berpengaruh terhadap kinerja Tendik. Nilai R-Square untuk kepuasan adalah 0,458 . Artinya, motivasi kerja dan iklim kerja mempunyai kontribusi positif terhadap kepuasan $45,8 \%$ dan 54,2\% dipengaruhi oleh faktor lain. Selanjutnya, nilai R-Square untuk kinerja Tendik IPB adalah 0,028 . Artinya, kinerja Tendik IPB dipengaruhi secara positif oleh kepuasan kerja sebesar 2,8\% dan 97,2\% dipengaruhi oleh faktor lain.
\end{abstract}

Kata kunci: iklim kerja, kepuasan kerja, motivasi kerja, tenaga kependidikan, SEM

\footnotetext{
${ }^{1}$ Alamat Korespondensi:

Email: diyanti.ipb@gmail.com
} 


\section{PENDAHULUAN}

Sumber daya manusia (SDM) memiliki peran penting sebagai potensi penggerak seluruh aktivitas organisasi. Setiap organisasi harus bisa menjaga, memelihara dan meningkatkan kualitas kinerja SDM. Salah satu cara yang dapat dilakukan oleh perusahaan dalam meningkatkan kualitas kinerja adalah dengan memberikan perhatian berupa motivasi kerja kepada karyawannya dan menciptakan iklim kerja yang baik. Selain itu, hal terpenting yang harus dilakukan oleh organisasi, adalah bagaimana karyawan dapat menikmati pekerjaannya sehingga karyawan dapat mengerjakan perkerjaannya tanpa ada tekanan.

Institut Pertanian Bogor (IPB) sebagai salah satu institusi yang bergerak dalam bidang pendidikan memiliki peran sangat besar dalam menghasilkan SDM kompeten dibidangnya. Dalam rangka mewujudkan SDM IPB yang siap dalam menjawab tantangan di masa depan, tentu tidak terlepas dari peran SDM yang ada di dalamnya, yaitu dosen dan tendik IPB di dalam penyelenggaraannya. Untuk itu diperlukan SDM bermotivasi kerja tinggi sehingga tercapai kepuasan kerja yang didukung oleh iklim kerja untuk meningkatkan kinerja institusi, serta tercapainya visi dan misi IPB dalam menuju World Class University (WCU).

Upaya IPB dalam mencapai WCU ditandai dengan perubahan IPB dari Perguruan Tinggi Negeri (PTN) menjadi Perguruan Tinggi Badan Hukum (PTNBH) sejak tahun 2000 berdasarkan Peraturan Pemerintah (PP) Nomor 154 Tahun 2000 tentang Penetapan IPB sebagai Badan Hukum Milik Negara atau BHMN. Dengan PTNBH, IPB memiliki kemampuan pengelolaan untuk memperoleh kemandirian, otonomi dan tanggungjawab yang lebih besar, di antaranya mengembangkan kemampuan sivitas akademika dan pegawai institut.

Tenaga kependidikan (Tendik) sebagai salah satu SDM yang memiliki peran strategik dalam memberikan pelayanan, baik kepada mahasiswa maupun dosen perlu memiliki kompetensi memadai. Pencapaian kinerja yang diharapkan, memerlukan motivasi kerja dari Tendik yang didukung oleh iklim kerja baik, sehingga diharapkan tercapainya kepuasan kerja. Upaya peningkatan kinerja Tendik terus dilakukan oleh IPB dibawah koordinasi Direktorat (Dit.) SDM melalui peningkatan kesejahteraan pegawai (dosen dan Tendik). Upaya-upaya tersebut dilakukan melalui tambahan insentif berbasis kinerja, baik kepada Tendik maupun tenaga dosen berdasarkan sistem merit. Tambahan insentif untuk Tendik diberikan setiap bulan, namun saat ini pembayaran insentif dilakukan setiap tiga bulan, Bantuan Hari Raya tidak hanya diberikan kepada PNS, tetapi juga diberikan kepada tenaga honorer. Kesejahteraan lain yang diberikan IPB berupa asuransi kesehatan rawat inap, baik Askes Sosial PNS maupun komersial dan fasilitas-fasilitas lain yang mendukung dalam pekerjaan. Namun, pada kenyataannya pemberian insentif kepada Tendik saat ini belum sesuai dengan Peraturan Pemerintah Nomor 107 Tahun 2013 tentang Tunjangan Kinerja Bagi Pegawai Di Lingkungan Kementerian Pendidikan dan Kebudayaan sebagaimana tunjangan kinerja yang diterima oleh Pegawai Negeri Sipil (PNS) Tendik di Perguruan Tinggi Negeri Satuan Kerja (PTN Satker).

Penilaian kinerja Tendik di IPB diterapkan berdasarkan Surat Edaran Direktur SDM IPB Nomor 243/I3.23/ $\mathrm{KP} / 2010$ tanggal 8 Januari 2010 tentang perubahan sistem penilaian kinerja Tendik IPB. Penilaian kinerja dilakukan dengan tujuan memberikan umpan balik atas kinerja yang telah diberikan individu kepada organisasi, mengidentifikasikan kekuatan dan kelemahan individu, menghargai kinerja individu, mengidentifikasikan pencapaian tujuan, evaluasi faktor pendorong pada tujuan, mengidentifikasi tujuan pelatihan, mengembangkan komunikasi dan membantu pimpinan dalam pengambilan keputusan.

Penilaian kinerja Tendik sudah di atas rata-rata, namun belum mencerminkan kinerja cukup baik, dikarenakan penilaian produktivitas yang dilakukan oleh atasan langsungnya belum obyektif. Data penilaian kinerja yang diperoleh dari Laporan Tahunan Direktorat Sumber Daya Manusia (Dit. SDM) IPB tahun 2015 (Tabel 1) menggambarkan bahwa masih ada Tendik IPB yang memperoleh penilaian kurang dari 3, yaitu artinya belum memenuhi standar penilaian kinerja, kondisi tersebut mengalami peningkatan $7,42 \%$ dari Tahun 2013 ke Tahun 2014 walaupun mengalami penurunan di Tahun 2015, yaitu 2,61\%. Tendik IPB yang tidak memperoleh penilaian juga mengalami peningkatan nyata dari Tahun 2014 ke Tahun 2015, yaitu dari 30 orang meningkat menjadi 190 orang (10\%). Secara keseluruhan Tahun 2015, penilaian kinerja Tendik IPB mengalami penurunan $3,2 \%$ dari tahun sebelumnya. 
Tingginya jumlah Tendik yang tidak memperoleh nilai kinerja dan tidak adanya Tendik yang memperoleh nilai A Tahun 2013 sampai Tahun 2015 menunjukkan bahwa kinerja Tendik belum mencapai hasil yang diharapkan oleh IPB. Jika kondisi ini dibiarkan, maka pada akhirnya akan berdampak bagi kinerja IPB, karena kinerja organisasi tergantung dari kinerja individu yang ada dalam organisasi tersebut. Berdasarkan kondisi tersebut, peneliti tertarik melakukan penelitian berjudul Pengaruh Motivasi Kerja dan Iklim Kerja Terhadap Kepuasan Kerja dan Implikasinya terhadap Kinerja Tenaga Kependidikan Institut Pertanian Bogor.

Kajian empiris yang relevan dengan motivasi kerja, kepuasan kerja dan iklim kerja terhadap kinerja pegawai di beberapa organisasi digunakan oleh peneliti sebagai pedoman dan melakukan kajian teori, serta metode yang digunakan untuk penelitian yang akan dilakukan antara lain: Penelitian Larasati dan Gilang (2014), penelitian ini bersifat deskriptif dan kausal. Analisis data yang digunakan adalah analisis deskriptif, analisis regresi linear berganda, uji hipotesis secara simultan (uji F), uji hipotesis secara parsial (uji t) dan koefisien determinasi. Dari kuesioner dengan 180 orang responden, didapatkan penilaian karyawan terhadap motivasi kerja dan kinerja dalam kategori sangat tinggi. Dari hipotesis disimpulkan Motivasi Kerja (X) yang terdiri dari Kebutuhan Prestasi (X1), Kebutuhan Afiliasi (X2) dan Kebutuhan Kekuasaan (X3) secara simultan dan parsial berpengaruh nyata terhadap Kinerja Karyawan (Y). Koefisien determinasi (R2) 0.551 menunjukkan besarnya pengaruh motivasi kerja terhadap kinerja karyawan $55,1 \%$ dan sisanya (44,9\%) dipengaruhi faktor-faktor lain yang tidak diteliti. Penelitian dengan peubah motivasi kerja terhadap kinerja juga dilakukan oleh Mahardhika et al. (2013) dengan hasil penelitian menunjukan bahwa motivasi berpengaruh nyata terhadap kinerja karyawan.

Penelitian lain yang berkaitan dengan motivasi kerja, kepuasan kerja dan iklim kerja diteliti oleh Muogo dan Uju (2013) dengan penelitiannya yang berjudul The Influence of Motivation on Employees' Performance: A Study Of Some Selected Firm in Anambra State. Penelitian ini bertujuan untuk menganalisis pengaruh dari motivasi intrinsik dan ekstrinsik terhadap kinerja karyawan yang ada di beberapa perusahaan di negara bagian Anambra. Kuesioner disebar ke 63 responden yang dipilih dari 21 perusahaan. Penelitian ini menggunakan statistik deskriptif dengan korelasi pearson untuk analisis data. Hasil dari penelitian ini menyatakan bahwa motivasi ekstrinsik diberikan kepada pekerja di sebuah organisasi memiliki pengaruh nyata terhadap kinerja pekerja, namun juga menunjukkan tidak ada hubungan nyata motivasi intrinsik seperti pujian, rekomendasi, menerima pekerja dan kinerjanya. Penelitian dengan peubah motivasi kerja, kepuasan kerja terhadap kinerja juga dilakukan oleh Firmansyah (2015), Juniantara (2015), Pratiwi (2013), Kumar dan Garg (2011), Tella et al. (2007), Bwire et al. (2014), Saleem dan Mahmood (2010) dan Arshadi (2010) dengan hasil yang menunjukan hubungan positif dari motivasi, kepuasan kerja dan kinerja.

Tabel 1. Rekapitulasi nilai kinerja Tendik tahun 2013-2015

\begin{tabular}{|c|c|c|c|c|c|c|c|}
\hline \multirow[b]{2}{*}{ Kisaran Nilai } & \multirow[b]{2}{*}{ Nilai } & \multicolumn{2}{|c|}{ Tahun 2013} & \multicolumn{2}{|c|}{ Tahun 2014} & \multicolumn{2}{|c|}{ Tahun 2015} \\
\hline & & $\begin{array}{l}\text { Jumlah } \\
\text { (orang) }\end{array}$ & $\begin{array}{c}\text { Persentase } \\
(\%)\end{array}$ & $\begin{array}{l}\text { Jumlah } \\
\text { (orang) }\end{array}$ & $\begin{array}{c}\text { Persentase } \\
(\%)\end{array}$ & $\begin{array}{l}\text { Jumlah } \\
\text { (orang) }\end{array}$ & $\begin{array}{c}\text { Persentase } \\
(\%)\end{array}$ \\
\hline 5 & A & - & - & - & - & - & - \\
\hline $4-<5$ & B & 1.154 & 78,29 & 1.013 & 72,43 & 1.169 & 74,18 \\
\hline $3-<4$ & $\mathrm{C}$ & 221 & 14,99 & 248 & 17,35 & 176 & 11,17 \\
\hline $2-<3$ & $\mathrm{D}$ & 9 & 0,61 & 112 & 7,84 & 16 & 1,02 \\
\hline $1-<2$ & E & 1 & 0,07 & 4 & 0,28 & 25 & 1,59 \\
\hline \multicolumn{2}{|c|}{ Tidak Mendapat Nilai } & 36 & 6,04 & 30 & 2,10 & 190 & 12,06 \\
\hline \multicolumn{2}{|c|}{ Total } & 1.474 & 100 & 1.429 & 100 & 1.576 & 100 \\
\hline
\end{tabular}


Analisis Pengaruh Iklim Organisasi dan Motivasi Terhadap Kinerja Pegawai Melalui Peubah Intervening Kepuasan Kerja diteliti oleh Widyastuti (2004). Penelitian ini dilakukan pada Dinas Pertanian Kota Semarang dengan menggunakan contoh sebanyak 117 pegawai. Analisis Structural Equation Modeling (SEM) digunakan untuk membuktikan hipotesis adanya pengaruh iklim organisasi terhadap motivasi, kepuasan kerja dan kinerja pegawai, serta pengaruh kepuasan kerja terhadap kinerja pegawai. Hasil penelitian menyatakan iklim organisasi berpengaruh positif terhadap motivasi pegawai, juga iklim organisasi berpengaruh positif terhadap kepuasan kerja dan kinerja pegawai. Di sisi lain ditunjukkan motivasi berpengaruh positif terhadap kepuasan kerja dan kinerja pegawai. Hal lainnya diperoleh kepuasan kerja berpengaruh positif terhadap kinerja pegawai. Hasil penelitian ini menunjukkan kurang kuatnya peubah kepuasan kerja. Relevansi penelitian terlihat pada tujuan dan metode yang digunakan. Lain halnya dengan hasil penelitian Dhermawan et al. (2012) yang menunjukkan bahwa motivasi dan lingkungan kerja berpengaruh tidak nyata terhadap kepuasan kerja, sementara kompetensi dan kompensasi berpengaruh nyata. Motivasi dan kompetensi berpengaruh tidak nyata terhadap kinerja pegawai sementara lingkungan kerja, kompensasi dan kepuasan kerja berpengaruh nyata. Penelitian terdahulu yang menggunakan peubah iklim organisasi dilakukan juga oleh Alugoro (2002), Bhaesajsanguan (2010), Chaur-luh (2014), Castro dan Martins (2010), Noordin et al. (2010). Hasil penelitian-penelitian tersebut menunjukkan iklim organisasi memiliki pengaruh terhadap kepuasan kerja yang pada akhirnya akan berpengaruh juga terhadap kinerja organisasi.

Perbedaan penelitian terdahulu dengan penelitian yang dilakukan dapat dilihat dari tiga hal, yaitu obyek penelitian (Pada umumnya, obyek penelitian terdahulu adalah karyawan di suatu perusahaan, pegawai di instansi pemerintah dan ada yang menggunakan dosen sebagai obyek penelitiannya. Dalam penelitian ini, obyek penelitian yang digunakan adalah Tendik di IPB); Penelitian ini menggunakan tiga peubah yaitu motivasi kerja, kepuasan kerja, iklim kerj dan kinerja. Selanjutnya, indikator kinerja yang digunakan dalam penelitian ini diambil penilaian kinerja Tendik IPB yang terdiri dari empat komponen penilaian, yaitu kehadiran, produktivitas, mutu kerja dan nilai unit kerja sehingga data yang digunakan adalah data sekunder.
Tujuan penelitian adalah menganalisis pengaruh motivasi kerja terhadap kepuasan kerja Tendik IPB, menganalisis pengaruh iklim kerja terhadap kepuasan kerja Tendik IPB, dan menganalisis pengaruh kepuasan kerja terhadap kinerja Tendik IPB.

\section{METODE PENELITIAN}

Penelitian dilakukan di Institut Pertanian Bogor Kampus IPB Darmaga Bogor melalui survei terhadap Tendik di lingkungan Kantor, Direktorat dan Biro. Pengumpulan data penelitian dilakukan pada bulan Februari-April 2016.

Data yang digunakan dalam penelitian ini adalah data primer dan data sekunder. Data primer diperoleh berdasarkan hasil pengisian kuesioner, wawancara dan observasi langsung yang dilakukan peneliti sendiri kepada Tendik. Kuesioner digunakan untuk mengukur motivasi kerja, kepuasan kerja dan iklim kerja Tendik untuk analisis kuantitatif. Skala yang digunakan untuk mengukur hasil tanggapan responden adalah skala Likert. Tanggapan responden yang mendukung pernyataan diberi skortertinggi (5), dan untuk tanggapan tidak mendukung diberi skor terendah (1). Data primer yang diperoleh dari hasil pengisian kuesioner oleh responden diolah dan ditabulasikan dengan Microsoft Excel 2010.

Data sekunder peroleh dari database kepegawaian, data penilaian kinerja Tendik tahun 2013-2015 dan laporan tahunan yang ada di Dit. SDM. Data sekunder lain diperoleh dari studi pustaka dari penelitian terdahulu yang bersumber dari jurnal, tesis, disertasi, buku referensi, internet, peraturan perundang-undangan dan surat keputusan yang relevan dengan penelitian.

Penelitian ini merupakan penelitian deskriptif kuantitatif dan analisis kuantitatif peubah seperti motivasi kerja, kepuasan kerja, iklim kerja dan kinerja Tendik di IPB. Untuk mendapatkan data primer digunakan pengisian kuesioner oleh responden. Analisis deskriptif digunakan untuk mendeskripsikan karakteristik demografi Tendik IPB yang digunakan sebagai contoh. Contoh atau sampel dalam penelitian ini adalah Tendik berstatus PNS yang ada di unit Kantor, Direktorat dan Biro di lingkungan IPB yang berjumlah 301 orang. Pengambilan besarnya contoh dalam penelitian ini menggunakan Rumus Slovin 
(Umar, 2004). Melalui rumus tersebut diperoleh contoh 172 responden dan untuk proporsi pengambilan contoh, digunakan proportionate random sampling.

Analisis pengaruh motivasi kerja dan iklim kerja terhadap kepuasan kerja dan implikasinya terhadap kinerja Tendik IPB digunakan Structural Equational Modelling - Partial Least Square (SEM - PLS). Jogiyanto (2011) menyatakan bahwa SEM-PLS berbasis ragam dan secara simultan melakukan pengujian terhadap model pengukuran (measurement model) dan model struktural (structural model). SEMPLS juga mengukur konstruk yang dapat dibentuk secara reflektif maupun formatif.

Model Pengukuran (outer model) dilakukan untuk menilai validitas dan reliabilitas model. Kriteria untuk menilai model pengukuran yaitu validitas konvergen (convergen validity), validitas diskriminan (discriminant validity), composite reliability. Uji validitas konvergen dalam PLS dengan indikator reflektif dinilai berdasarkan loading factor indikator yang mengukur kontruk tersebut. Ukuran refleksif individual dinilai tinggi jika berkorelasi lebih dari 0,70 dengan konstruk yang diukur. Chin (1998) dalam Ghozali (2008) mengatakan untuk tahap awal penelitian bisa digunakan skala pengukuran nilai loading 0,5-0,6 akan dianggap cukup. Uji validitas diskriminan merupakan pengukuran indikator refleksif berdasarkan cross loading dengan peubah latennya. Metode lain dengan membandingkan nilai Square root of average variance extracted (AVE) setiap peubah dengan korelasi antar peubah lainnya dalam model. Jika nilai pengukuran awal kedua metode tersebut lebih baik dibandingkan dengan nilai peubah lainnya dalam model, maka dapat disimpulkan bahwa peubah tersebut memiliki nilai discriminant validity yang baik atau sebaliknya. Composite reliability mengukur nilai sesungguhnya reliabilitas suatu konstruk. Rule of thumb nilai cronbach's alpha dan composite reliability harus lebih besar dari 0,7 meskipun nilai 0,6 masih dapat diterima (Hair et al.2008)

Model struktural (Inner model) untuk memprediksi hubungan kausalitas antar peubah laten. Model ini dievaluasi dengan menggunakan R-Square untuk konstruk dependen, nilai koefisien path atau t-value tiap path untuk tingkat nyata dalam pengujian hipotesis. Makin tinggi nilai R-Square maka model akan semakin baik.
Berdasarkan landasan teori dan pemikiran terdahulu serta kerangka pemikiran yang telah dijelaskan sebelumnya maka disusun hipotesis penelitian sebagai berikut berikut: H1(Motivasi kerja berpengaruh terhadap kepuasan kerja Tendik IPB); H2 (Iklim kerja berpengaruh terhadap kepuasan kerja Tendik IPB); H3 (Kepuasan kerja berpengaruh terhadap kinerja Tendik IPB).

Hipotesis ini memiliki arti bahwa diduga semakin tinggi motivasi kerja maka kepuasan kerja akan meningkat sehingga kinerja Tendik akan meningkat. Demikian juga dengan iklim kerja, diduga bahwa iklim kerja yang baik akan meningkatkan kepuasan kerja sehingga kinerja Tendik akan meningkat. Sebaliknya, diduga jika motivasi kerja menurun maka kepuasan kerja akan menurun sehingga kinerja Tendik akan menurun. Demikian juga dengan iklim kerja, diduga jika iklim kerja tidak kondusif maka kepuasan kerja akan menurun sehingga kinerja Tendik akan menurun.

Berdasarkan permasalahan dan teori yang telah diuraikan maka perlu adanya pemikiran penelitian guna membahas permasalahan-permasalahan tersebut. Untuk mengetahui adanya pengaruh motivasi kerja dan iklim kerja terhadap kepuasan kerja dan implikasinya terhadap kinerja Tendik di IPB, disusun kerangka pemikiran penelitian pada Gambar 1.

\section{HASIL}

\section{Uji Validitas dan Realiabilitas}

Uji validitas digunakan agar kuesioner yang dipakai dalam penelitian ini dapat berfungsi dengan baik. Kuesioner yang digunakan untuk uji validitas 40 kuesioner, kemudian diuji untuk mengetahui tingkat validitas. Sebuah instrumen dikatakan valid, apabila mampu mengukur apa yang hendak diukur/diinginkan dan dapat mengungkap data dari peubah yang diteliti. Hasil uji validitas dan realiabilitas pada 40 responden menunjukkan bahwa nilai $\mathrm{r}$ hitung $>\mathrm{r}$ tabel dan nilai Cronbach's Alpha lebih dari 0,6. Suatu instrumen penelitian dikatakan valid jika $r$ hitung $>r$ tabel. Pada uji coba ini dimana $\mathrm{N}=40$ pada taraf nyata $5 \%$ atau probabilitas 0,05 maka $r$ tabel adalah 0,304. Seluruh instrumen dalam penelitian ini memiliki nilai Cronbach Alpha pada kisaran 0,707-0,869. 


\section{Pengaruh Motivasi Kerja dan Iklim Kerja terhadap Kepuasan Kerja dan Implikasinya Terhadap Kinerja Tendik IPB}

Evaluasi model PLS dilakukan dengan mengevaluasi outer model dan Inner model. Outer model merupakan model pengukuran untuk menilai validitas dan reliabilitas model. Melalui proses iterasi logaritma, paramater model pengukuran (validitas konvergen, validitas diskriminan, composite reliability dan cronbach's alpha) diperoleh termasuk nilai $\mathrm{R}^{2}$ sebagai parameter ketetapan model prediksi. Inner model merupakan model struktural untuk memprediksi hubungan kausalitas antar peubah laten. Melalui proses bootstraping, parameter uji T-statistic diperoleh untuk memprediksi adanya hubungan kausalitas (Jogiyanto, 2011).

\section{Evaluasi Model Pengukuran (Outer Model)}

Validitas konvergen dalam PLS dengan indikator reflektif dinilai berdasarkan loading factor (korelasi skor item atau skor komponen dengan skor konstruk) indikator-indikator yang mengukur konstruk tersebut. Ukuran rekleksif individual dikatakan valid jika memiliki loading $(\lambda)$ dengan peubah laten yang akan diukur $\geq 0,5$. Jika salah satu indikator memiliki nilai loading ( $\lambda$ ) maka indikator tersebut harus dibuang (drop) karena akan mengindikasikan bahwa indikator tersebut tidak cukup baik untuk mengukur peubah laten dengan tepat.

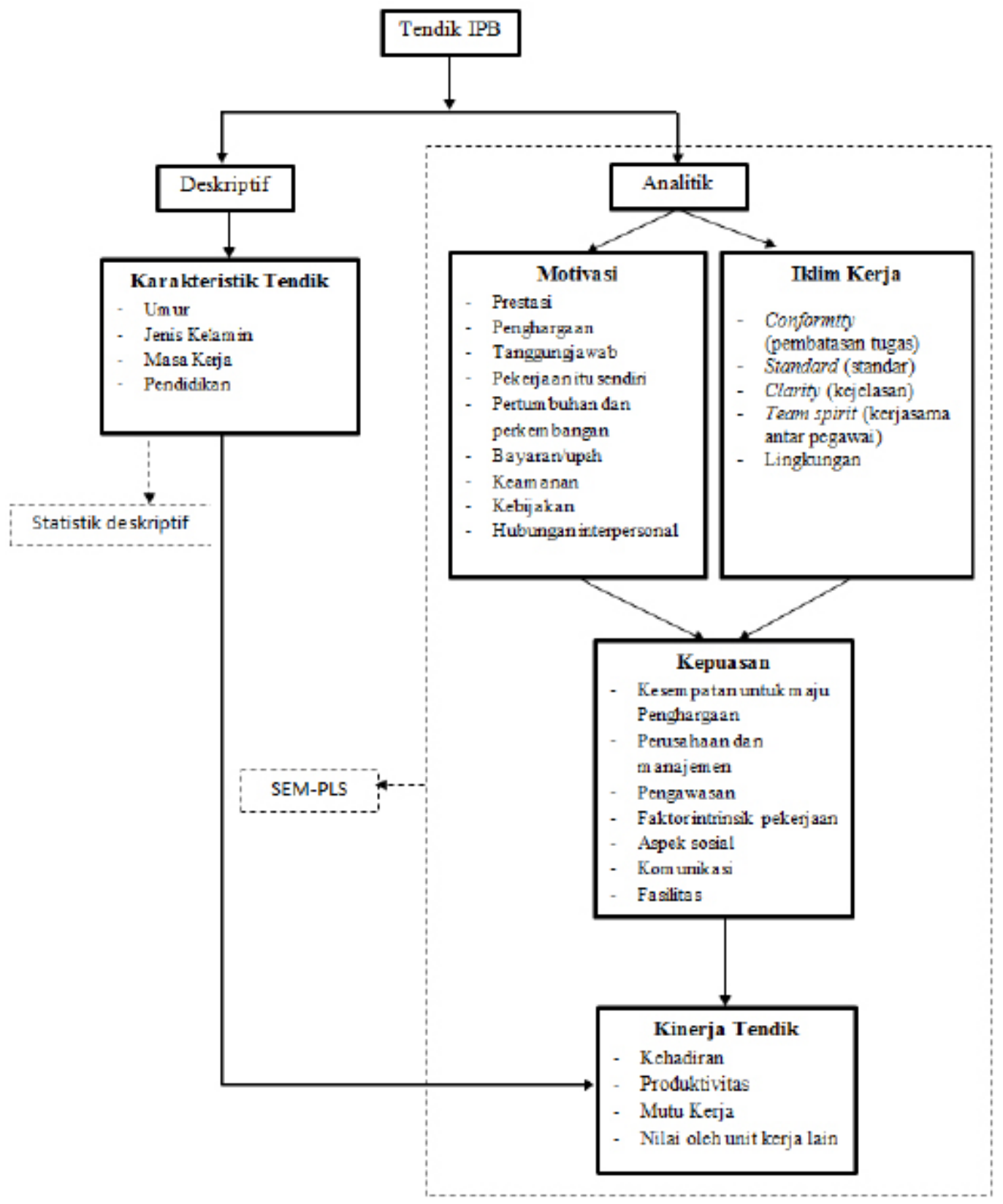

Gambar 1. Kerangka pemikiran penelitian 
Dalam penelitian ini digunakan batas loading factor 0,5. Nilai loading factor pada penelitian ini menggunakan software SmartPLS. Hasilnya menunjukkan ada empat peubah yang memiliki nilai loading factor $<0,5$ yaitu X11, X15, X21, X24,Y13, $\mathrm{Y} 14$. Indikator yang memiliki nilai outer loading $>0,5$ maka indikator model pengukuran ini valid. Peubah motivasi kerja yang memiliki nilai outer loading $>0,5$ adalah X12 (Penghargaan), X13 (Tanggungjawab), X14 (pekerjaan itu sendiri), X16 (bayaran/upah), X17 (Keamanan), X18 (Kebijakan) dan X19 (hubungan interpersonal). Indikator X19 (hubungan interpersonal) merupakan ukuran terkuat dari peubah motivasi kerja karena memiliki nilai outer loading paling besar $(0,7635)$. Indikator yang tidak digunakan karena memiliki nilai $<0,5$ yaitu X11 (Prestasi) dan X15 (Pertumbuhan dan perkembangan).

Peubah iklim kerja yang memiliki nilai outer loading $>0,5$ adalah X22 (Standar/ Standard), X23 (Kejelasan/ Clarity) dan X25 (Lingkungan). Indikator X23 (Kejelasan/Clarity) merupakan ukuran terkuat dari peubah iklim kerja karena memiliki nilai outer loading paling besar $(0,7685)$. Indikator yang tidak digunakan karena memiliki nilai $<0,5$, yaitu X21 (Pembatasan tugas/Conformity) dan X24 (Kerja sama antar pegawai/ Team spirit).

Peubah kepuasan kerja yang memiliki nilai outer loading $>0,5$ adalah Y11 (Kesempatan untuk maju), Y12 (Perusahaan dan manajemen), Y15 (Aspek sosial), Y16 (Komunikasi) dan Y17 (Fasilitas) maka ke lima indikator ini merupakan indikator yang valid dari peubah kepuasan kerja. Indikator Y16 (Komunikasi) merupakan ukuran terkuat dari peubah kepuasan kerja karena memiliki nilai outer loading paling besar (0.7789). Indikator yang tidak digunakan karena memiliki nilai $<0,5$, yaitu Y13 (Pengawasan) dan Y14 (Faktor intrinsik pekerjaan).

Peubah kinerja Tendik IPB yang memiliki nilai outer loading $>0,5$ adalah Y21 (Kehadiran), Y22 (produktivitas), Y23 (mutu kerja) dan Y24 (nilai oleh unit lain). Indikator Y23 (mutu kerja) merupakan ukuran terkuat dari peubah kinerja Tendik IPB karena memiliki nilai outer loading paling besar $(0,7445)$. Ke empat indikator ini merupakan indikator valid sebagai pengukur peubah kinerja Tendik IPB. Validitas diskriminan dilakukan untuk memastikan bahwa setiap konsep dari peubah laten berbeda dengan peubah lainnya. Model dikatakan memiliki validitas diskriminan yang baik, jika akar kuadrat Average Variance Extracted (AVE) untuk setiap konstruk lebih tinggi dari korelasi antara dua konstruk di dalam model. Tabel 2 menunjukkan nilai akar kuadrat dari AVE. Dari Tabel 3 diketahui bahwa akar AVE (diagonal) lebih tinggi dari korelasi antar konstruk lainnya (baca kolom ke bawah), sehingga semua konstruk dapat dikatakan memiliki discriminant validity tinggi. Evaluasi yang dilakukan untuk crossloading adalah indikator memiliki nilai loading yang lebih besar terhadap konstruk (peubah laten) asal.

Composite reliability mengukur nilai sesungguhnya reliabilitas suatu konstruk dan dinilai lebih baik dalam mengestimasi konsistensi internal suatu konstruk. Composite reliability harus lebih besar dari 0,7 (Hair et al. 2008). Dalam penelitian ini, peubah dikatakan cukup reliabel bila peubah tersebut mempunyai nilai Composite reliability $>0,7$ (Tabel 3 ).

Tabel 2. Validitas diskriminan

\begin{tabular}{lcccccc}
\hline \multirow{2}{*}{ Peubah } & \multicolumn{3}{c}{ AVE } & \multicolumn{3}{c}{ Korelasi } \\
\cline { 2 - 7 } & AVE & VAVE & Iklim kerja & Kepuasan kerja & Kinerja tendik & Motivasi kerja \\
\hline Iklim kerja & 0,5269 & 0,7259 & 1 & & & \\
Kepuasan kerja & 0,4118 & 0,6417 & 0,4941 & 1 & 1 & \\
Kinerja tendik & 0,8380 & 0,9154 & 0,0939 & 0,1670 & 0,0712 & 1 \\
Motivasi kerja & 0,4459 & 0,6677 & 0,5311 & 0,6542 & 0 \\
\hline
\end{tabular}

Tabel 3. Composite reliability

\begin{tabular}{lcc}
\hline & Konstruk & Composite reliability \\
\hline Iklim kerja & 0,769144 \\
Kepuasan kerja & 0,774096 \\
Kinerja tendik & 0,807379 \\
Motivasi kerja & 0,843733 \\
\hline
\end{tabular}


Berdasarkan Tabel 3 semua konstruk memiliki Composite reliability $>0,7$, artinya model memiliki reliabilitas yang baik. Hasil evaluasi secara keseluruhan, baik validitas konvergen, validitas diskriminan dan Composite reliability maka dapat disimpulkan indikator-indikator sebagai pengukur peubah laten sebagai pengukur yang valid dan reliabel.

\section{Evaluasi model struktural (Inner Model )}

Evaluasi Inner model dilakukan untuk mengevaluasi pengaruh konstruk antar laten dan pengujian hipotesis. Evaluasi ini dilakukan untuk melihat hubungan antara peubah, nilai nyata dan R-Square dari model penelitian. Tahap ini dilakukan dengan melihat nilai R-Square untuk peubah endogen dan membandingkan t-hitung dengan tabel (t-tabel pada selang kepercayaan 1.96). Pengujian hipotesis dilakukan dengan melihat analisis bootstrapping pada path coefficients, yaitu membandingkan t-hitung dengan t-tabel. Jika nilai t-hitung $>$ t-tabel $(1,96)$, maka hipotesis diterima, namun jika nilai t-hitung $<$ t-tabel $(1,96)$, maka hipotesis ditolak. Gambar 2 menunjukkan bahwa covariance pengukuran indikator oleh konstruk laten yang digambarkan dengan bentuk elips dengan beberapa anak panah dari konstruk ke indikator. Model ini menunjukkan bahwa perubahan pada konstruk laten akan memengaruhi perubahan pada indikator.

Tabel 4 menunjukkan bahwa nilai R-Square untuk kepuasan adalah 0,458. Artinya, motivasi kerja dan iklim kerja mempunyai kontribusi positif terhadap kepuasan 45,8\% dan sisanya (54,2\%) dipengaruhi oleh faktor lain. R-Square untuk kinerja tendik IPB adalah 0,028. Artinya, kinerja tendik IPB dipengaruhi secara positif oleh kepuasan sebesar $2.8 \%$ dan sisanya $(97,2 \%)$ dipengaruhi oleh faktor lain. Output PLS bootstrapping disajikan pada Gambar 2.

Hasil olah smartPLS menghasilkan nilai original sample (o) yang merupakan nilai koefisien jalur dan nilai t-statistik untuk menunjukkan tingkat nyata. Pembahasan dari uji hipotesis tersebut adalah sebagai berikut:

Tabel 4. Nilai R-square

\begin{tabular}{lc}
\hline \multicolumn{1}{c}{ Peubah } & R-square \\
\hline Kepuasan kerja & 0,458 \\
Kinerja tendik & 0,028 \\
\hline
\end{tabular}

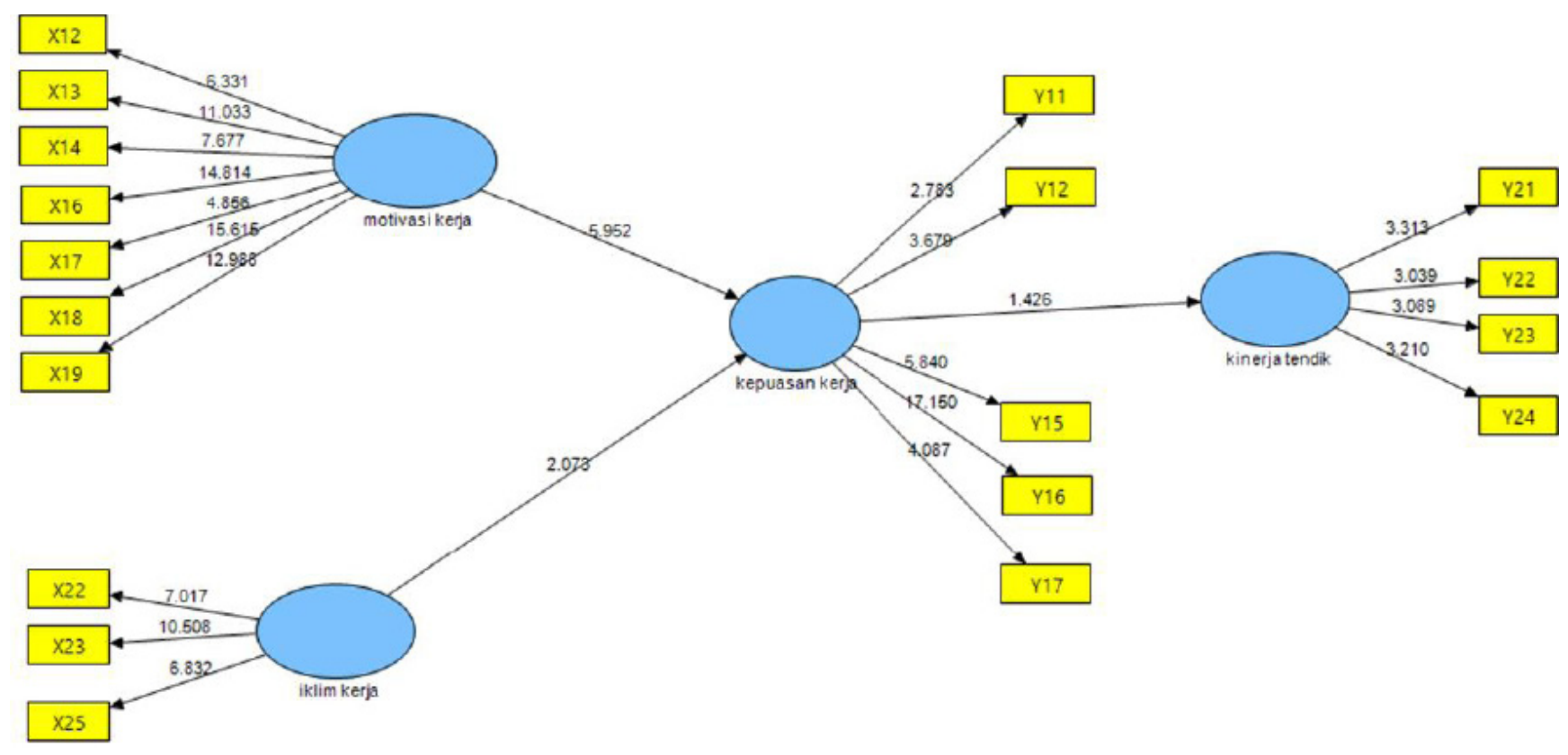

Gambar 2. Output proses PLS bootstrapping 
Hipotesis 1: Motivasi Kerja Berpengaruh pada Kepuasan Kerja

Tabel 5 menunjukkan motivasi kerja berpengaruh nyata terhadap kepuasan kerja. Hal ini dibuktikan dengan nilai koefisien parameter positif pada contoh original 0,5457 artinya, jika motivasi kerja meningkat maka kepuasan kerja akan meningkat pula dan sebaliknya, apabila motivasi kerja menurun maka kepuasan kerja menurun. Hasil P-value $(0,000)$ menunjukkan bahwa motivasi kerja berpengaruh nyata terhadap kepuasan kerja pada taraf alpha 1\%, maka hipotesis 1 dapat diterima. Motivasi kerja yang dibentuk dari indikator penghargaan, tanggung jawab, pekerjaan itu sendiri, bayaran, keamanan, kebijakan dan hubungan interpersonal memiliki pengaruh terhadap kepuasan kerja Tendik. Hasil penelitian yang sejalan dengan penelitian ini dibuktikan oleh Kumar dan Garg (2011) bahwa ada hubungan nyata secara statistik dari tiga peubah independen (gaji, fasilitas, dan promosi) dengan peubah dependen, yaitu kepuasan kerja. Hasil penelitian juga menggambarkan bahwa di antara peubah independen, gaji adalah peubah yang paling penting dan lebih berpengaruh. Ada hubungan langsung dan positif faktor motivasi dengan kepuasan kerja karyawan. Hasil penelitian Karmita et al. (2015) dan Ogunnaike et al. (2014) mengemukakan hasil yang sama bahwa motivasi kerja memiliki pengaruh yang positif dan nyata terhadap kepuasan kerja.
Hipotesis 2 : Iklim Kerja Berpengaruh pada Kepuasan Kerja

Tabel 5 menunjukkan iklim kerja berpengaruh nyata terhadap kepuasan kerja. Hal ini dibuktikan dengan nilai koefisien parameter positif pada contoh original 0,2043 artinya jika iklim kerja baik maka kepuasan kerja akan meningkat dan sebaliknya, apabila iklim kerja tidak baik, maka kepuasan kerja akan menurun. Hasil P-value (0.051) menunjukkan bahwa motivasi kerja berpengaruh nyata terhadap kepuasan kerja pada taraf alpha 5\% maka hipotesis 1 dapat diterima.

Iklim kerja dibentuk dari indikator standar, kejelasan dan lingkungan memengaruhi kinerja Tendik. Indikator standar berhubungan dengan standar yang sudah ditentukan unit kerja, kejelasan berhubungan dengan arah, tujuan unit erja yang tertuang dalam program kerja unit dan tugas pokok dan fungsi Tendik IPB sehari-hari. Sedangkan lingkungan berhubungan dengan tempat dimana tendik bekerja, lingkungan yang nyaman jauh dari bising kendaraan, polusi dan lingkungan yang asri dengan penataan ruang yang baik. Hasil penelitian yang sejalan dengan penelitian ini dibuktikan oleh Castro dan Martin (2010) bahwa ada hubungan positif antara iklim organisasi dan kepuasan kerja dan dengan demikian, terlepas dari bagaimana dimensi yang dirasakan, iklim organisasi memiliki pengaruh terhadap kepuasan kerja. Penelitian yang sama juga dilakukan oleh Widyastuti (2010) bahwa iklim organisasi berpengaruh terhadap kepuasan, motivasi berpengaruh positif terhadap kinerja karyawan dan kepuasan kerja. Kepuasan kerja berpengaruh positif terhadap kinerja pegawai.

Tabel 5 Nilai bootstrapping

\begin{tabular}{lcccccc}
\hline \multicolumn{1}{c}{ Hubungan } & Koefisien & $\begin{array}{c}\text { Standard error } \\
(\text { STERR })\end{array}$ & $\begin{array}{c}\text { T statistics } \\
(\mid \text { O/STERR } \mid)\end{array}$ & P-value & Keterangan & Kesimpulan \\
\hline $\begin{array}{l}\text { Motivasi kerja } \rightarrow \\
\text { Kepuasan kerja }\end{array}$ & 0,5457 & 0,0920 & 5,9318 & 0,000 & $\begin{array}{c}\text { Signifikan alpha } \\
1 \%\end{array}$ & Diterima \\
$\begin{array}{l}\text { Iklim kerja } \rightarrow \\
\text { Kepuasan kerja }\end{array}$ & 0,2043 & 0,1035 & 1,9744 & 0,051 & $\begin{array}{c}\text { Signifikan alpha } \\
10 \%\end{array}$ & Diterima \\
$\begin{array}{l}\text { Kepuasan kerja } \rightarrow \\
\text { Kinerja tendik }\end{array}$ & 0,1670 & 0,0909 & 1,8361 & 0,069 & Signifikan alpha & Diterima \\
\hline
\end{tabular}


Hipotesis 3 : Kepuasan Kerja Berpengaruh pada Kinerja Tendik IPB

Tabel 5 menunjukkan kepuasan kerja berpengaruh nyata terhadap kinerja Tendik IPB. Hal ini dibuktikan dengan nilai koefisien parameter positif pada contoh sample 0,1670. Artinya, jika kepuasan kerja meningkat, maka kinerja Tendik IPB akan meningkat dan sebaliknya, apabila kepuasan kerja menurun, maka kinerja Tendik IPB akan menurun. Hasil P-value $(0,069)$ menunjukkan kepuasan kerja berpengaruh nyata terhadap kinerja kerja pada taraf alpha $10 \%$ maka hipotesis 1 dapat diterima. Hasil penelitian ini sejalan dengan penelitian yang dilakukan oleh Bwire et al. (2014) yang membuktikan bahwa ada hubungan positif motivasi karyawan dengan kepuasan kerja, juga hubungan positif kepuasan kerja dengan kinerja organisasi. Motivasi karyawan dan kepuasan kerja keduanya berhubungan positif dengan kinerja organisasi. Hasil penelitian lain yang sejalan dengan penelitian ini adalah penelitian yang dilakukan oleh Rasdini et al. (2014), Raharjo (2015) dan Fadli et al. (2012) bahwa kepuasan kerja berpengaruh positif dan nyata terhadap kinerja karyawan.

\section{Implikasi Manajerial}

Implikasi teori dari hasil penelitian ini menunjukkan bahwa teori-teori motivasi kerja, iklim kerja berhubungan dengan kinerja Tendik IPB melalui kepuasan kerja. Penghargaan saat ini kurang dirasakan oleh Tendik IPB. Pemberian penghargaan bukan saja dalam bentuk materi misalnya kenaikan gaji atau kenaikan insentif saja, tapi ucapan-ucapan yang akan memberikan perasaan dihargai atas apa yang selama ini dilakukan.

Iklim kerja yang baik harus dibentuk oleh beberapa faktor, namun dalam penelitian ini, kejelasan (clarity), yaitu persepsi Tendik bahwa unit kerjanya dikelola dengan baik, dan tujuan dirumuskan dengan jelas untuk memberikan keteraturan di dalamnya. Untuk itu, POB yang ada diunit kerja dilaksanakan dengan baik dan diikuti oleh penjaminan mutu sehingga POB tidak keluar dari koridornya. Penjaminan mutu secara berkelanjutan bertujuan memberikan pelayanan yang baik dan berkualitas kepada dosen IPB maupun mahasiswa IPB sebagai pelanggan atau pengguna jasa. Kepuasan kerja dilihat dari indikator kesempatan untuk maju dapat tercapai kepuasan dan berimplikasi pada kinerja Tendik IPB. Peningkatan kapasitas sumber daya
Tendik melalui pemantapan jenjang karir Tendik IPB. Upaya yang bisa dilakukan oleh IPB membuat standar pengembangan karir dengan penetapan SK Rektor, yang kemudian dibuat petunjuk teknis. Bentuk pelaksanaan peningkatan jenjang karir dapat berupa perpindahan posisi yang sejajar atau satu rumpun jabatan yang sama, baik dalam kelompok jabatan administrasi maupun fungsional, perpindahan posisi ke posisi lebih tinggi dari kelompok jabatan administrasi maupun fungsional dan perpindahan PNS dari posisi jabatan administrasi ke fungsional. Peningkatan kompetensi Tendik IPB dilakukan melalui pelatihan untuk setiap jabatan fungsional atau kelompok pekerjaan. Selama ini program pelatihan hanya berdasarkan masukan dari unit kerja. Peningkatan kompetensi tendik dapat dilakukan dengan memberikan beasiswa bagi Tendik IPB yang melanjutkan studinya

\section{KESIMPULAN DAN SARAN}

\section{Kesimpulan}

Hasil analisa penelitian yang telah diuraikan, dapat disimpulkan bahwa motivasi kerja berpengaruh secara nyata terhadap kepuasan kerja, karena motivasi mempunyai nilai koefisien parameter yang nyata dan positif. Hal tersebut mencerminkan motivasi kerja melalui indikator-indikatornya, apabila ditingkatkan maka dapat meningkatkan kepuasan kerja Tendik IPB. Selanjutnya, Iklim kerja berpengaruh secara nyata terhadap kepuasan kerja, karena iklim kerja mempunyai nilai koefisien parameter yang nyata dan positif. Hal tersebut menunjukkan bahwa ikim kerja melalui indikator-indikatornya, apabila ditingkatkan maka akan meningkatkan kepuasan kerja Tendik IPB. Di samping itu, kepuasan kerja berpengaruh secara nyata terhadap kinerja Tendik IPB, karena kepuasan mempunyai nilai koefisien parameter yang nyata dan positif. Hal tersebut mencermikan kepuasan kerja apabila ditingkatkan maka akan dapat meningkatkan kinerja Tendik IPB.

\section{Saran}

Penelitian bisa dikembangkan dengan obyek penelitian yang lebih luas misalnya tenaga honorer IPB atau dosen IPB berstatus PNS sehingga hasil penelitian dapat dibandingkan. Penelitian dapat diperluas dengan mempertimbangkan peubah lain atau memperdalam 
peubah yang sudah ada dengan indikator lain. Penelitian perlu dilakukan secara berkala untuk melihat indikatorindikator yang mungkin bisa berubah sejalan dengan dinamika yang terjadi di IPB.

\section{DAFTAR PUSTAKA}

Alugoro KS. 2002. Pengaruh iklim kerja terhadap kepuasan kerja pegawai di Sekretariat Daerah Semarang [tesis]. Semarang:UNDIP.

Arshadi N. 2010. Basic need satisfaction, work motivation and job performance in an industrial company In Iran. Procedia Social and Behavioral Science 5(2010):1267-1272. https:// doi.org/10.1016/j.sbspro.2010.07.273.

Bhaesajsanguan S.2010. The relationships among organizational climate, job satisfaction and organizational commitment in the Thai Telecommunication Industri. E-Leader Singapore Journal 10:1-15.

Bwire J, Ssekakubo J, Lwanga F, Ndiwalana G. 2014. Employee motivation job satisfaction and organizational performance in Uganda oil sub sector. Global Advanced Research Journal of Management and Business Studies 3(7):315324.

Castro ML, Martins N. 2010. The relationship between organisational climate and employee satisfaction in a South African Information And Technology Organization. SA Journal of Industrial Psychology 36(1):1-9. https://doi.org/10.4102/ sajip.v36i1.800.

Chaur-luh. 2014. The Organizational climate and employees' job satisfaction in the Terminal Operation Context of Kaohsiung Port. The Asian Journal of Shipping and Logistics 30(3):373392. https://doi.org/10.1016/j.ajs1.2014.12.007.

[Dit. SDM IPB] Direktorat Sumber Daya Manusia IPB. 2010.Surat Edaran Direktur Sumberdaya Manusia IPB Nomor 243/I3.23/K/2010 tanggal 8 Januari 2010 tentang Perubahan Sistem Penilaian Kinerja Tendik IPB. Bogor:IPB.

Dhermawan, Sudibya, Utama. 2012.Pengaruh motivasi, lingkungan kerja, kompetensi dan kompensasi terhadap kepuasan kerja dan kinerja pegawai di lingkungan Kantor Dinas Pekerjaan Umum Provinsi Bali. Jurnal Manajemen, Strategi Bisnis dan Kewirausahaan 6(2):173-183.

Firmansyah. 2015. Motivasi, kepuasan kerja dan kinerja penyuluh kehutanan di Kabupaten Cianjur Jawa
Barat [tesis]. Bogor: Institut Pertanian Bogor.

Fadli UM, Martini N, Diana N. 2012. Pengaruh kepuasan kerja terhadap kinerja dosen Universitas Singaperbangsa Karawang. Jurnal Manajemen 9(2):678- 704.

Hair J, Tatham LR, Anderson RE, Black W. 2008. Multivariate Data Analysis Ed ke-6. New York: Person Prentice Hall.

Juniantara IW. 2015. Pengaruh motivasi dan kepuasan kerja terhadap kinerja karyawan koperasi di Denpasar [tesis]. Denpasar: Udayana Denpasar.

Kumar N, Garg P. 2011. Impact of motivational factors on employee's job satisfaction- A study on some selected organization in Punjab, India. Asian Jurnal Of Management Reasearch 3(1):672683.

Karmita SB, Supartha IWG, Priantini PS. 2015. Pengaruh motivasi kerja dan penempatan karyawan terhadap kepuasan kerja dan kinerja karyawan (studi pada analis kredit PT. BPD Bali Cabang Utama Denpasar). E-Jurnal Ekonomi dan Bisnis 4(12):947-974.

Larasati S, Gilang A. 2014. Pengaruh motivasi kerja terhadap kinerja karyawan wilayah Telkom Jabar Barat Utara (Witel Bekasi). Jurnal Manajemen dan Organisasi 5(3): 200-213.

Mahardhika, Hamid. Ruhana. 2013. Pengaruh motivasi kerja terhadap kinerja karyawan (survei karyawan pada PT. AXA Financial Indonesia Sales Office Malang). Jurnal Administrasi Bisnis 4(2):1-10.

Muogo, Uju S. 2013. The influence of motivation on employees' performance: a study of some selected firms in Anambra State. AFRREV International Journal of Arts and Humanities 2(3):134-151.

Noordin F, Omar S, Sehan S, Idrus S. 2010. Organizational climate and its influence on organizational commitment. International Business \& Economics Reasearch Journal 9(2):1-9. https://doi.org/10.19030/iber.v9i2.516.

Pratiwi SD. 2013. Pengaruh motivasi, kepuasan kerja, gaya kepemimpinan kepala sekolah menurut persepsi guru, dan iklim sekolah terhadap kinerja guru ekonomi SMP Negeri Di Kabupaten Wonogiri. Jurnal Pendidikan Insan Mandiri 1(1):89-100.

Ogunnaike O, Akinbola OA, Ojo OA. 2014. Effect of motivation on job satisfaction of selected Sales representatives. Journal of Educational and Social Research 4(1):197-203. https://doi. org/10.5901/jesr.2014.v4n1p197. 
Rasdini I, Gutha IW, Gama K. 2014. Pengaruh imbalan, kepuasan kerja dan iklim organisasi terhadap kinerja dosen jurusan keperawatan Politeknik Kesehatan Denpasar. Jurnal Skala Husada 11(1):1-5.

Raharjo KS. 2015. Pengaruh kepuasan kerja, motivasi dan remunerasi terhadap kinerja pegawai (studi pada Kantor Pengadilan Negeri Yogyakarta) [tesis]. Yogyakarta: Universitas Muhammadiyah Yogyakarta.

Saleem R, Mahmood A. 2010. Effect of work motivation on job satisfaction in mobile telecommunication service organizations of Pakistan. International
Journal of Business and Management 5(11):213222. https://doi.org/10.5539/ijbm.v5n11p213.

Tella A, Ayeni CO, Popoola SO. 2007. Work motivation, job satisfaction, and organisational commitment of library personnel in academic and research libraries in Oyo State, Nigeria. Library Philosophy and Practice (e-journal) 9(2):1-16.

Widyastuti EN. 2004. Analisis pengaruh iklim organisasi dan motivasi terhadap kinerja pegawai melalui peubah intervening kepuasan kerja (studi empiris pada Dinas Pertanian Kota Semarang) [tesis]. Semarang:UNDIP Semarang. 